\title{
Marine Heat Waves Hazard 3D Maps and the Risk for Low Motility Organisms in a Warming Mediterranean Sea
}

\section{OPEN ACCESS}

Edited by:

Iris Eline Hendriks,

University of the Balearic Islands,

Spain

Reviewed by:

Thibaut de Bettignies,

Museum National d'Histoire Naturelle,

France

Simon Morley,

British Antarctic Survey, UK

Gabriel Jorda,

University of the Balearic Islands,

Spain

*Correspondence: Cosimo Solidoro

csolidoro@inogs.it

Specialty section:

This article was submitted to Global Change and the Future Ocean,

a section of the journal

Frontiers in Marine Science

Received: 21 December 2016 Accepted: 24 April 2017

Published: 11 May 2017

Citation:

Galli G, Solidoro C and Lovato T (2017) Marine Heat Waves Hazard 3D

Maps and the Risk for Low Motility

Organisms in a Warming

Mediterranean Sea.

Front. Mar. Sci. 4:136.

doi: 10.3389/fmars.2017.00136

\author{
Giovanni Galli ${ }^{1}$, Cosimo Solidoro ${ }^{1,2 *}$ and Tomas Lovato ${ }^{3}$
}

${ }^{1}$ National Institute of Oceanography and Experimental Geophysics (OGS), Sgonico, Italy, ${ }^{2}$ International Centre for Theoretical Physics, Trieste, Italy, ${ }^{3} \mathrm{ODA}$ - Ocean Modeling and Data Assimilation, Fondazione Centro Euro-Mediterraneo sui

Cambiamenti Climatici, Lecce, Italy

Frequency and severity of heat waves is expected to increase as a consequence of climate change with important impacts on human and ecosystems health. However, while many studies explored the projected occurrence of hot extremes on terrestrial systems, few studies dealt with marine systems, so that both the expected change in marine heat waves occurrence and the effects on marine organisms and ecosystems remain less understood and surprisingly poorly quantified. Here we: (i) assess how much more frequent, severe, and depth-penetrating marine heat waves will be in the Mediterranean area in the next decades by post-processing the output of an ocean general circulation model; and (ii) show that heat waves increase will impact on many species that live in shallow waters and have reduced motility, and related economic activities. This information is made available also as a dataset of temperature threshold exceedance indexes that can be used in combination with biological information to produce risk assessment maps for target species or biomes across the whole Mediterranean Sea. As case studies we compared projected heat waves occurrence with thermotolerance thresholds of low motility organisms. Results suggest a deepening of the survival horizon for red coral (Corallium rubrum, a commercially exploited benthic species already subjected to heat-related mass mortality events) and coralligenous reefs as well as a reduction of suitable farming sites for the mussel Mythilus galloprovincialis. In recent years Mediterranean circalittoral ecosystems (coralligenous) have been severely and repeatedly impacted by marine heat waves. Our results support that equally deleterious events are expected in the near future also for other ecologically important habitats (e.g., seagrass meadows) and aquaculture activities (bivalvae), and point at the need for mitigation strategies.

Keywords: marine heat waves, mass mortalities, hazard assessment, climate forecast, coralligenous, mussels, seagrass meadows

\section{INTRODUCTION}

Climate change is expected to alter not only the average values of environmental properties, but also the extreme ones, as well as the frequency of occurrence of conditions nowadays considered as extreme (Seneviratne et al., 2014). This has the potential to significantly impact the state and dynamics of biological organisms by exposing them to conditions that are different from those they 
are adapted to, and potentially outside their tolerance limits. Many organisms have the capabilities to acclimate and/or adapt to new conditions (Buckley et al., 2001; Middlebrook et al., 2008; Haguenauer et al., 2013; Thompson et al., 2013), and biological adaptation via natural selection and/or evolution may even accelerate under a fast-changing environment, to the point of allowing an impacted population to persist (evolutionary rescue, Thompson, 1998; Bell, 2012); However, in most cases this may not be fast enough to counterbalance the effects of climate change (Bell, 2012), especially in slow growing species with relatively low population growth rates. Furthermore, while phenotypic plasticity can provide means for individuals to acclimate to adverse conditions, this is possible only within certain limits and, in any case, it comes at an energetic cost and leaves an organism stressed and more vulnerable to other pressures (Haguenauer et al., 2013). Therefore, both acclimation and adaptation mechanisms are likely to counterbalance slow gradual changes, but may be less effective in buffering the impact of extreme or episodic events.

Model projections indicate, on land, an intensification of hot extremes throughout the Mediterranean area (Déqué et al., 2007; Diffenbaugh et al., 2007) whereas no such analysis is currently available for the Mediterranean marine environment, except for limited regions and/or depths (e.g., Jordà et al., 2012; Marbà et al., 2015).

Marine heat waves (MHWs) can be qualitatively defined as discrete anomalously warm events that last for a prolonged period of time. They might be severe because of the level of temperature, the duration of the event, or both. From a purely geophysical perspective, heat-waves might be defined with respect to the "typical" values of a site/time, i.e., as anomalies in respect to climatological values (Hobday et al., 2016). However, if one is interested in MHW impacts on biological organisms, species-specific thermal thresholds related to physiological performance of organisms are more relevant than those related to climatological values (e.g., an anomalously warm period during the cold season might not be as impacting on biological activity as one occurring during the hot season). Therefore, in the following we will define as MHW an event of $\mathrm{d}^{*}$ contiguous days in which a temperature threshold $\mathrm{T}^{*}$ is exceeded.

As MHWs are generally a consequence of elevated air temperature, impacts are generally limited to the upper portion of the water column. Effects can be especially relevant for those organisms that, being sessile or having reduced motility, cannot move to colder water. Ecosystem range shifts and extirpation of marginal populations as a consequence of MHWs are reported worldwide. Extreme MHWs in temperate Western Australia determined an $\sim 100 \mathrm{~km}$ range contraction in kelp forests and their (apparently stable) replacement with subtropical and tropical species (Smale and Wernberg, 2013; Bennett et al., 2015; Wernberg et al., 2016). In 2016 record high temperatures triggered an unprecedented mass coral bleaching event that severely affected approximately one third of the Great Barrier Reef in NE Australia (Great Barrier Reef Marine Park Authority, 2016). The Mediterranean Sea is no exception; notable examples of significant impacts of heat waves on Northwestern Mediterranean marine ecosystems are provided by the 1999, 2003 summers, which were characterized by mass mortality outbreaks in a variety of hard substrate macroinvertebrates including anthozoans, sponges, bryozoans, ascidians, and bivalves (Garrabou et al., 2001, 2009; Crisci et al., 2011). The effects of the 1999 and 2003 events have been extensively studied from the points of view of thermal regimes characterization (e.g., Bensoussan et al., 2010; Crisci et al., 2011), organism (e.g., Bally and Garrabou, 2007; Torrents et al., 2008), and populations (e.g., Bramanti et al., 2005; Cupido et al., 2009; Garrabou et al., 2009) response at local scales. Less severe events were reported locally also in 2006 and 2008 (Bensoussan et al., 2010; Huete-Stauffer et al., 2011). Among the proposed cause and effect mechanisms, energetic constraints (Rossi and Tsounis, 2007; Coma et al., 2009) and pathogens outbreaks (Martin et al., 2002; Bally and Garrabou, 2007; Vezzulli et al., 2010) are supported by evidence. However, whatever the immediate cause of death or damage, it is generally accepted that such events are triggered by uncommonly high temperatures (Marbà and Duarte, 2010; Crisci et al., 2011).

All of the aforementioned studies focus primarily on octocoral species, mainly because a substantial amount of research was carried out, after mortality outbreaks, about the effects of thermal extremes on those species. However, evidence suggests that impacts could be substantial in the near future also for other important shallow water ecosystems, such as seagrass meadows: Marbà and Duarte (2010) uncovered a warminginduced trend of increasing shoot mortality and reduced recruitment rates for Posidonia oceanica meadows in the Balearic Islands. Model projections indicate that, even under a mild greenhouse gas emission scenario, P. oceanica meadows from western Mediterranean are at risk of extinction by the middle of this century (Jordà et al., 2012).

Similarly, heat waves will impact on organisms that are exploited by aquaculture activities, since they are kept in surface water by floating cages (e.g., fishes) or devices (e.g., bivalves). A questionnaire-based study of Mediterranean mollusc producers (Rodrigues et al., 2015) from 12 coastal regions and 6 countries highlighted how episodes of partial or total mortality related to high water temperature are currently widespread; other studies (Anestis et al., 2007, 2010; Gazeau et al., 2014) identified the threshold of $25^{\circ} \mathrm{C}$ as critical for mussels physiological activities, indicating that Mediterranean mussels may already live close to their physiological limits.

Risk analysis is derived by combining hazard, exposure and vulnerability. In accordance with the definition given by IPCS (2004), we refer to hazard as the inherent property of a situation having the potential to cause adverse effects, depending on the position (and therefore actual exposure) of the object considered, and on its response to the actual exposure (vulnerability). In our case, we refer to the situation of sea water warming and the occurrence of marine heat waves, which is a function of geomorphological, meteorological, and hydrodynamic properties (hazard). The objects considered are different kinds of marine organisms, each kind characterized by a given space distribution and a species specific response to temperature (vulnerability). As far as mortality events caused by MHWs are concerned, it is in principle possible to produce risk assessment maps for 
target organisms (or for a community), by combining threedimensional daily temperature fields produced by numerical models (the hazard layer) with the physiological knowledge on thermotolerance thresholds and information on species geographical distribution (the vulnerability layer). The main focus of this paper is the hazard layer (so this is not intended to be a risk assessment); however, a purely physical evaluation may fail to reveal biologically significant signals (e.g., an analysis on temperature extremes may not identify prolonged exposure to sublethal temperatures). With this in mind, we chose to analyze three-dimensional temperature fields by means of metrics related to Mediterranean species thermotolerance.

To the best of our knowledge, Mediterranean Sea oceanic projections suitable to perform a MHWs assessment are currently lacking. In fact, previous multi-model exercise carried out in CIRCE project (Gualdi et al., 2013) and the current ensemble of Med-CORDEX initiative (Ruti et al., 2016) provide threedimensional seawater temperatures only as monthly fields. In this work, daily seawater temperature projections were retrieved from the dataset produced during the EU project MedSeA (http://medsea-project.eu/) and cover the period 2000-2050 under RCP8.5 scenario conditions. We remark that several uncertainties may arise from using a single dataset and a multimodel ensemble would indeed allow to identify the envelope of potential changes in future seawater temperatures. To this regard, a comparison with regional ocean reanalysis from Copernicus Marine Environment Monitoring Service (http:// marine.copernicus.eu/) was carried out to better constrain the reliability of the MedSeA dataset under contemporary climate conditions.

We consider a selection of thermal thresholds relevant for the Mediterranean marine environment and quantify how frequently and intensively such thresholds are exceeded under current (2001-2010) and future (2041-2050) conditions over the whole Mediterranean and across depths.

As case studies we present maps of threshold exceedance for temperature and duration exposure values indicated as lethal for the mussel Mythilus galloprovincialis, the seagrass P. oceanica, and for the red coral Corallium rubrum, a key species of Mediterranean coralligenous habitats (Ballesteros, 2006). The response of the latter also provides indications on the response of coralligenous communities and, possibly, of other organisms that live at the edge of the summer thermocline and are adapted to similar temperature regimes.

Results described with those case studies represent a first approximation of potential risk that can be refined by incorporating more details on physiological responses of the target organisms, and/or applied to other species, provided the information on thermal limits and species distribution is available.

On this respect, we acknowledge that different response to heat waves can be detected also between conspecifics, depending on local adaptation/acclimation of individuals (e.g., Torrents et al., 2008; Haguenauer et al., 2013). However, while in principle different thresholds might be needed for different areas or depths, in practice the biological knowledge needed for such a fine implementation is rarely available for non-local scale, and the assessment obtained by applying a common threshold to large regions remains a useful approximation of potential impacts.

\section{MATERIALS AND METHODS}

\section{Projection Data and Temperature Regimes Analysis}

The daily three dimensional seawater temperature data were retrieved from a numerical simulation produced in the framework of the MedSeA project (EU Grant Agreement 265103, http://medsea-project.eu), herein referred as MedSea dataset. In particular, these data cover a 50 year long period, namely from 2000 to 2050, and represent the near-future changes of the Mediterranean Sea under the RCP8.5 IPCC scenario.

The ocean general circulation model used to generate this projection is NEMO (v3.4, Madec, 2008) and it was implemented with the parameterizations and numerical schemes thoroughly described in Oddo et al. (2009), therein referred as MFS_V2.2 configuration. Overall, the model grid has a horizontal resolution of $1 / 16$ of degree (which corresponds to about $6.5 \mathrm{~km}$ ) and a vertical $\mathrm{z}$-coordinate discretization in 72 levels, with spacing ranging from 3 meters in surface layers to 350 meters in the bottom ones. Boundary conditions come from the atmosphereocean global circulation model CMCC-CM (Scoccimarro et al., 2011) and account for 6-hourly atmospheric fields, daily fresh water discharges (rivers and Black Sea exchange), and monthly fields of temperature, salinity, and velocities prescribed at the open lateral boundaries (see also Lovato et al., 2013).

As MHWs are usually confined to shallow or relatively shallow waters, in this work we considered only data in the upper 50 $\mathrm{m}$, corresponding to 11 model vertical levels. Due to the limited span of the dataset, comparisons of present and future conditions were arbitrarily limited to 10 year long time windows, namely 2001-2010 and 2041-2050.

In order to evaluate the reliability of the MedSea data and better constrain uncertainties arising from the use of a single dataset, we performed a comparison of the data under contemporary climate conditions with the regional ocean reanalysis (herein Rean) from Copernicus Marine Environment Monitoring Service, cataloged as MEDSEA_REANALYSIS_PHYS_006_004 (http://marine. copernicus.eu). These data come from a state of the art system that integrates a modeling framework and data assimilation techniques to represent the state of the Mediterranean Sea.

The comparison with the reanalysis dataset addresses the occurrence of deviations in the mean state of the system by considering the difference in averaged temperatures, and the similarity of MHWs events in terms of maximum duration and number of occurrences (frequency) that exceeded three key temperature thresholds, namely 25,28 , and $30^{\circ} \mathrm{C}$ (see also Section Hazard Layers' Definition). For each parameter, we computed the mean, standard deviation, Mean Absolute Error (MAE) and Pearson correlation over two depth levels (5 and $29 \mathrm{~m}$ ) and by aggregating the data over 10 sub-basins of the Mediterranean Sea, which were defined in continuity with previous works (see Cossarini et al., 2015; Lazzari et al., 2016). In particular, basins are identified as follow: Northern and Southern Adriatic Sea (Adn, 
Ads), Aegean Sea (Aeg), Alboran Sea (Alb), Ionian Sea (Ion), Levantine basin(Lev), North Western Mediterranean (Nwm), Eastern and Western South Western Mediterranean (Swe, Sww), and Tyrrenian Sea (Tyr).

Annual temperature anomalies were also computed from the MedSeA dataset over the whole Mediterranean basin and compared to the CIRCE ensemble (Gualdi et al., 2013) over the period 2000-2050 to further verify the consistence of the mean state trend in the near future.

Finally, we present the average and the 95th percentile of seawater temperature difference between the selected time windows to provide a general characterization of temperature regimes changes under future climate projection.

\section{Hazard Layers' Definition}

The Mediterranean Sea sub-basins are characterized by widely different thermal regimes to which autochthonous species are locally adapted. To account for this variability, we consider several temperature thresholds in the range $20-32^{\circ} \mathrm{C}$. Such range is inclusive of most of the summer temperature values found in Mediterranean surface waters, including those associated with biological impacts.

Results on MHW frequency and severity are summarized as:

(i) Duration of the longest lasting MHW among those characterized by a temperature threshold $\mathrm{T}^{*}$, in a 10 year period for each $\mathrm{x}, \mathrm{y}, \mathrm{z}$ point $\left[\mathrm{D}_{\mathrm{T}^{*}}(\mathrm{x}, \mathrm{y}, \mathrm{z})\right]$. Duration maps are computed for a set of $\mathrm{T}^{*}$.

(ii) Average of the duration all MHWs characterized by a temperature threshold $\mathrm{T}^{*}$, regardless the duration, in a 10 year period for each $\mathrm{x}, \mathrm{y}, \mathrm{z}$ point $\left[\mathrm{A}_{\mathrm{T}^{*}}(\mathrm{x}, \mathrm{y}, \mathrm{z})\right]$. Average duration maps are computed for a set of $\mathrm{T}^{*}$

(iii) Frequencies of occurrence of all MHWs warmer than a given temperature $\mathrm{T}^{*}$, regardless their duration (that is lasting more than 1 day), in a 10 year period, for each $\mathrm{x}, \mathrm{y}, \mathrm{z}$ point $\left[\mathrm{F}_{\mathrm{T}^{*}, 1}(\mathrm{x}, \mathrm{y}, \mathrm{z})\right]$. Frequencies maps are computed for a set of $\mathrm{T}^{*}, \mathrm{~d}^{*}$ pairs.

(iv) Frequencies of occurrence of MHWs warmer than a given temperature $\mathrm{T}^{*}$ and lasting more than a contiguous period $\mathrm{d}^{*}$, in a 10 year period, for each $\mathrm{x}, \mathrm{y}, \mathrm{z}$ point $\left[\mathrm{F}_{\mathrm{T}^{*}, \mathrm{~d}^{*}}(\mathrm{x}, \mathrm{y}, \mathrm{z})\right]$. Frequencies maps are computed for a set of $\mathrm{T}^{*}, \mathrm{~d}^{*}$ pairs.

This information defines a set of hazard maps, which are given partly in the text, partly in the Supplementary Materials S1, S2. The data are also available from the authors upon request.

In the following, as examples of our approach, we focus on three specific hazard layers related to the reference temperatures of 25,28 , and $30^{\circ} \mathrm{C}$. As detailed in the following paragraphs, these hazard layers are considered to be representative of the vulnerability for selected target species from markedly different biomes: the red coral C. rubrum, the seagrass $P$. oceanica, and the mussel M. galloprovincialis. Moreover, such temperatures encompass the range of extreme summer temperatures found in Mediterranean surface waters across latitudinal gradients.

In each of the three hazard layers we focus on the information about the maximal event duration, which is compared with critical threshold durations relevant for our target species. In addition, we compute, in each reference period and map point, the frequency of occurrence of MHWs whose duration exceeds the critical threshold values. Note that, frequencies of other specific MHWs can be computed if interested in other organisms.

\section{Case Study 1. Hazard Layer for the Thermal Threshold of $25^{\circ} \mathrm{C}$}

Temperatures values around $25^{\circ} \mathrm{C}$ were associated with the 1999 and 2003 mortality outbreaks (Garrabou et al., 2009; Crisci et al., 2011) and were found to have lethal effects on several circalittoral benthic invertebrates upon moderate to prolonged duration exposure (Crisci et al., 2011). Also $25^{\circ} \mathrm{C}$ has been indicated as an upper limit to Mediterranean mussels normal physiological performance (Anestis et al., 2007, 2010; Gazeau et al., 2014). Here, in order to characterize our analysis, we focus on the biological information relative to the red coral C. rubrum.

C. rubrum is a slow growing, long lived, gorgonian coral endemic of the Mediterranean Sea. This coral is commonly found on hard substrates, on steep walls and overhangs, below $10 \mathrm{~m}$ depth (Rossi et al., 2008) and down to $800 \mathrm{~m}$ (Costantini et al., 2010), with the typical range being 25-60 m (Rossi et al., 2008). It is associated with the coralligenous communities (Tsounis et al., 2010), a collective term referring to complex biogenic structures made by the outgrowth of encrusting calcareous algae on hard substrate in the mesophotic zone. C. rubrum is exploited by the jewelry industry since ancient times for its glossy red skeleton and is currently considered over-harvested (Tsounis et al., 2010, 2013). In fact, populations down to $50 \mathrm{~m}$ are usually characterized by dense patches of small individuals as a consequence of selective harvesting of the large specimen (Tsounis et al., 2007; Santangelo and Bramanti, 2010; Cau et al., 2016). Besides fishing, C. rubrum populations above $30 \mathrm{~m}$ depth were severely affected by the 1999 and 2003 mass mortality events with percentage of affected colonies as high as $80 \%$ in some sites (Garrabou et al., 2001, 2009).

Upper thermal limits for C. rubrum have been estimated by Torrents et al. (2008). These authors submitted corals to elevated temperature treatments $\left(24,25,27\right.$, and $\left.30^{\circ} \mathrm{C}\right)$ after acclimation at $18^{\circ} \mathrm{C}$ and quantified the days required for mortality signs to appear in the tested specimen as well as the severity of mortality effects. Furthermore, different mortalities have been observed for specimen collected from shallow $(10 \mathrm{~m})$ vs. deep populations (40 $\mathrm{m})$. Deep corals were more sensitive to warming than the shallow ones, likely because the latter are adapted to warmer temperature than the former (Torrents et al., 2008; Haguenauer et al., 2013).

According to Torrents et al. (2008), upon an exposure to $25^{\circ} \mathrm{C}$ the first signs of mortality appear after 14 days in the shallow specimen and after 9 days in the deep specimen, whilst at temperatures $\geq 27^{\circ} \mathrm{C} 3-5$ days are sufficient to kill both shallow and deep populations. Here, we use the average of the duration exposure values identified by Torrents et al. (2008), 12 days, to characterize C. rubrum thermotolerance.

We neglect the classification of virulence that is reported by Torrents and coauthors (partial or total mortality), because a fine identification of impacts is beyond the scope of this study. In fact, our aim is to quantify present and expected frequency, intensity and depth penetration of the kind of anomaly indicated by Torrents et al. (2008) as critical for C. rubrum survival. 
A finer approach considering thermotolerance thresholds in the range $23-28^{\circ} \mathrm{C}$, applied to the red gorgonian Paramuricea clavata, can be found in Bensoussan et al. (2013) and Pairaud et al. (2014). Since $P$. clavata thermotolerance limits are very similar to those of C. rubrum (see Crisci et al., 2011 for a comparison), we argue that Bensoussan et al. (2013) and Pairaud et al. (2014) results are equally relevant for C. rubrum and possibly for other mesophotic macrobenthic invertebrates that in fact displayed similar mortality patterns (Perez et al., 2000; Garrabou et al., 2009; Crisci et al., 2011).

Since C. rubrum is absent or at best extremely rare in the Eastern Mediterranean Basin, where also the occurrence of temperature values $\geq 25^{\circ} \mathrm{C}$ is far more common than in the Western Basin, we limit the present analysis to the North Western Mediterranean and Adriatic seas.

\section{Case Study 2. Hazard Layer for the Thermal Threshold of $28^{\circ} \mathrm{C}$}

Temperature values around $28^{\circ} \mathrm{C}$ were found to be lethal for infralittoral species, such as mussels (Ramón et al., 2007) and seagrass (Marbà and Duarte, 2010) in the Western Mediterranean upon moderate to prolonged duration exposure. By comparison the same temperature values $\left(27-28^{\circ} \mathrm{C}\right)$ causes mortality in just a few days in circalittoral species (e.g., Torrents et al., 2008; Crisci et al., 2011). Marbà et al. (2015) found that 50\% of the reported impacts of warming in the Mediterranean Sea occur at surface temperatures $\geq 27.5^{\circ} \mathrm{C}$. To characterize our analysis, we focus here on biological information (vulnerability layer) relative to the mussel M. galloprovincialis and briefly discuss the implications also for the seagrass $P$. oceanica.

The Mediterranean mussel, M. galloprovincialis, is a bivalve. In the Mediterranean it is cultured mainly in Italy and Greece, but some production also takes place along the Mediterranean coasts of Spain, France, Eastern Adriatic countries and Turkey (FAO, 2010). Mediterranean mussel culture dates back to no later than 1901 (Tarragona) and it currently amounts to about 100,000 tons/y. Rearing of M. galloproncialis is always extensive (i.e., no food is added from outside), and in all cases mussel seeds are cultured in surface waters with nylon nets, rafts, wooden frames, or longlines of floating buoys.

In summer 2003 total mortality of mussels from a semienclosed bay in north eastern Spain was observed when seawater temperature reached $28^{\circ} \mathrm{C}$ for a period of 2 weeks, this being the first time that total mortality was observed at this site since mussel cultivation started in 1930 (Ramón et al., 2007). Gazeau et al. (2014) performed a long term warming experiment (with temperature reflecting natural variation with $\mathrm{a}+3^{\circ} \mathrm{C}$ offset) on M. galloprovincialis from the same area and also observed total mortality of the sample within few weeks when water temperature reached $28^{\circ} \mathrm{C}$.

By contrast the same temperature of $28^{\circ} \mathrm{C}$ has been found to impair physiological activity, but not to result in complete mortality of the sample (after 1-month exposure) for M. galloprovincialis from the Thermakios gulf in Greece (Anestis et al., 2007, 2010), indicating that those mussels may be adapted to tolerate higher temperatures. However, Anestis et al. (2007) still report about $30 \%$ mortality upon a 15 days exposure at $28^{\circ} \mathrm{C}$ and about 45\% after 30 days. In Anestis et al. (2007) experiments mussels were acclimated at $18^{\circ} \mathrm{C}$ and then submitted to constant temperature treatments with a $0.1^{\circ} \mathrm{C} / \mathrm{min}$ warming rate.

We use the thresholds of 15 and 30 days (hereafter moderate duration exposure and long duration exposure) to characterize the vulnerability of Mediterranean M. galloprovincialis to MHWs. In fact, in the near future, such kind of thermal anomalies, tough extreme, are predicted to become commonplace in many areas where mussels are currently cultivated.

\section{Case Study 3. Hazard Layer for the Thermal Threshold of $30^{\circ} \mathrm{C}$}

Temperature values $\geq 30^{\circ} \mathrm{C}$ are today uncommon in the Mediterranean and, unsurprisingly, evidence suggests this temperature to be extremely hazardous for Mediterranean species. Torrents et al. (2008) reported total mortality of C. rubrum upon an exposure of just 1 day to $30^{\circ} \mathrm{C}$ and, arguably, such temperature level might cause total collapse of circalittoral communities even for a very short-term exposure. It is however unlikely that such temperature levels will be reached in Mediterranean circalittoral environments, at least in the near future, but surface waters might still be impacted. Anestis et al. (2007) observed total mortality of a sample of M. galloprovincialis upon a 20 days exposure at $30^{\circ} \mathrm{C}$. We use this threshold exposure time to characterize the $30^{\circ} \mathrm{C}$ hazard layer.

\section{RESULTS}

\section{Change in Temperature Regimes in the Mediterranean Sea}

The reliability of the MedSea dataset under current climate conditions is here addressed through the comparison with the Rean data over the period 2000-2010 by first considering the mean and standard deviation of temperature fields and MHWs maximum duration and frequency at 5 and $29 \mathrm{~m}$ depth for three selected temperature thresholds (Figure S3.1).

As one can see, both mean and standard deviation of temperature fields for the two datasets are in good agreement across all sub-basins. The MHW maximal duration of the two datasets compares well for all the considered temperature thresholds and depth levels, while the standard deviation agrees to a lesser extent in the near-surface layer (Figures S3.1A,D). Conversely, MHW frequency data are more scattered with rather high values of standard deviation that are close to the mean differences (Figures S3.1B,E). Such a mismatch is likely related to the rather low number of MHW events per decade detected in both datasets.

Table S3.1 reports the MAE and Pearson's correlation statistics computed using the same sub-basins aggregation, temperature threshold, and depths as in Figure S3.1. The statistical correlation is further qualified by means of discrete intervals to highlight the degree of reliability within each sub-basin, according to the following criteria: negligible (0-0.3), low (0.3-0.5), moderate (0.5-0.7), high (0.7-1). MedSea mean temperature fields are generally in a good agreement with those of Rean, with the 
exception of the Alboran Sea regions that has a negligible correlation at $29 \mathrm{~m}$ depths. This may be partly attributed to some bias introduced in Atlantic surface waters by the lateral open boundary conditions, which is a critical issue in regional oceanic models (e.g., Oddo et al., 2009).

As far as maximal MHW duration is concerned, a good correlation is mainly found in the near-surface layer at the $25^{\circ} \mathrm{C}$ threshold, apart from the Northern Adriatic sub-basin that displays the lowest agreement between the two datasets. In this region, the influence of the Po River on the seawater temperature spatiotemporal viability is well known (Cushman-Roisin et al., 2001) and the runoff forcing originated by a global climate model (see Section Projection Data and Temperature Regimes Analysis) clearly has some limitations. MAE and correlation values for the other temperature threshold indicate a rather good correspondence of MHW duration in the central and eastern Mediterranean basins. It is worth to note that the number of events is significantly lower for 28 and $30^{\circ} \mathrm{C}$ thresholds, especially in western Mediterranean areas, thus leading to poorer values. In fact, MHW frequency for these temperature thresholds is almost everywhere lower than 2. Conversely, the correlation values of MHW frequency are relatively better for the $25^{\circ} \mathrm{C}$ threshold. Overall, the statistical metrics of $\mathrm{MHW}$ indicate a good reliability of maximal duration and frequency of events under contemporary climate conditions for the majority of Mediterranean Sea sub-basins.

A comparison of the MedSea sea surface temperature anomaly at the Mediterranean basin scale with that provided by the five regional models ensemble of CIRCE project is shown in Figure 1. The MedSea projections fall within the variability range of the ensemble, thus indicating a good consensus in expecting a warming trend of the Mediterranean Sea in the next decades.

When the two reference periods (2001-2010 and 2041-2050) are compared, future projections lead to an increase in average temperature of about $1^{\circ} \mathrm{C}$ (Figures $2 \mathbf{A}, \mathbf{C}$ ), a change that is consistent throughout the Mediterranean and at different depths. The 95th percentile temperatures exhibit a trend similar to the mean values (Figures 2B,D), especially in the near-surface layer where the change is of nearly $+1^{\circ} \mathrm{C}$ and it is rather homogenous over the entire basin. The variability of extreme temperatures at $29 \mathrm{~m}$ depth appears instead enhanced and cooling occurs at some locations.

The analysis of the MedSea dataset based on the fixed temperature thresholds in the range $20-32^{\circ} \mathrm{C}$ indicates an increase, under future conditions, in the number of threshold exceedance events, in their areal extent and depth penetration, and in their duration (one example for each computed $\mathrm{MHW}$ statistic is shown in Figure 3). This holds true for all temperature thresholds (see Figures 5-7 for temperature threshold 25, 28, and $30^{\circ} \mathrm{C}$, and the supporting information S2 for a selection of the other thresholds). This signal is stronger in the shallowest portion $(0-20 \mathrm{~m})$ of the water column, but along the eastern coasts of the Levantine Basin this effect is still evident down to about $40 \mathrm{~m}$ depth. Figure 4 shows the change in number of sites at all considered depths, for either C. rubrum presence records (Harmelin, 2006) or mussel culture facilities (location points from Rodrigues et al., 2015), where at least one of the considered MHWs occurred.

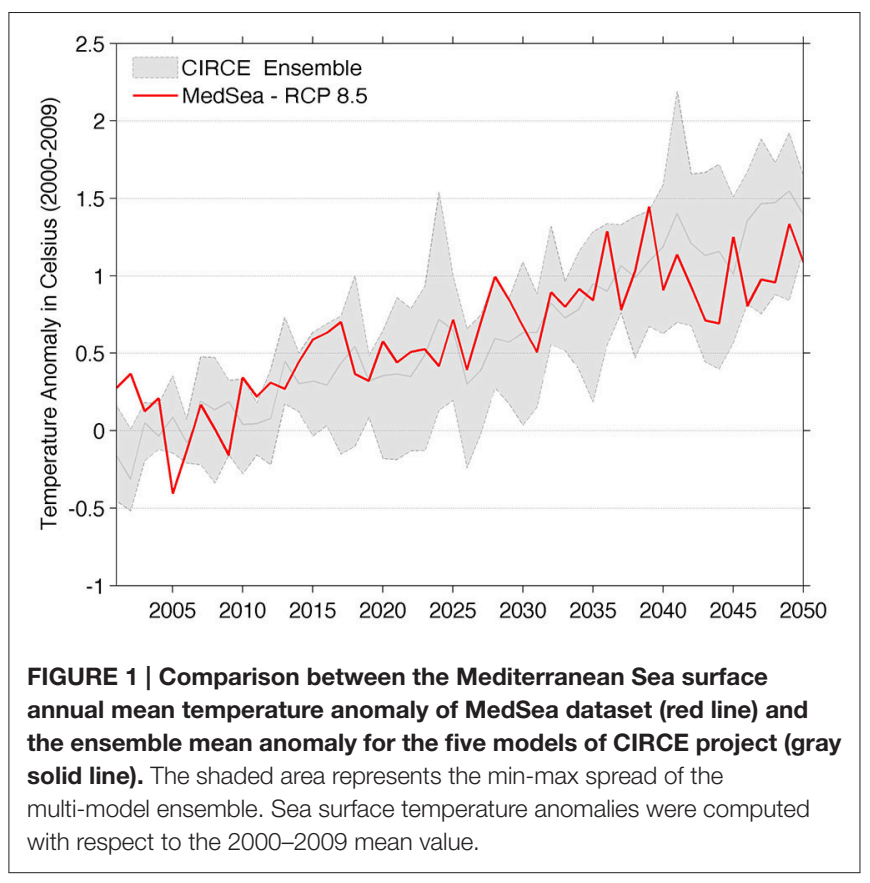

As our focus is on low motility (benthic) species, our maps are relevant just for a narrow strip along the coastline, however we choose to retain also the open sea for readers that might be interested in the epipelagic environment.

\section{Events with Temperature Exceeding $25^{\circ} \mathrm{C}$ in NW Mediterranean}

Under present conditions there is a good overlap between observed red coral mortality occurrences in NW Mediterranean and simulated hazard projected by the MedSea data (Figures 5A,C,E,G), even if the depth penetration of mortality risk appears underestimated. In fact, published reports (Garrabou et al., 2001, 2009; Bramanti et al., 2005) indicate noticeable C. rubrum mortality up to $30 \mathrm{~m}$ depth, while the simulated threshold exceedance events are detected in coastal areas below $20 \mathrm{~m}$ only in isolated spots, namely the gulf of Marseille and the western Italian coasts. On the other hand, the greatest depth penetration is seen in the central portion of Western Mediterranean, including the Spanish coasts, Balearic Islands, and Sardinia. This mismatch in observed vs. simulated depth penetration of MHWs was also present in the similar impact assessment (for the red gorgonian $P$. clavata) in Pairaud et al. (2014), which used temperature data from a finer scale (horizontal resolution $1.2 \mathrm{~km}$ ) physical model.

As far as the Eastern Basin is concerned (Figures S2.4-S2.6), most of coastal areas are interested by threshold exceedance events at all the considered depths (up to $46 \mathrm{~m}$ ). The reported absence of C. rubrum in the Eastern Basin could thus be linked also to an unfavorable thermal regime.

Under future conditions (Figures 4A, 5B,D,F,H) the MedSea data indicate areas interested by exceedance of the $25^{\circ} \mathrm{C}$ threshold to spread relative to current conditions and also 

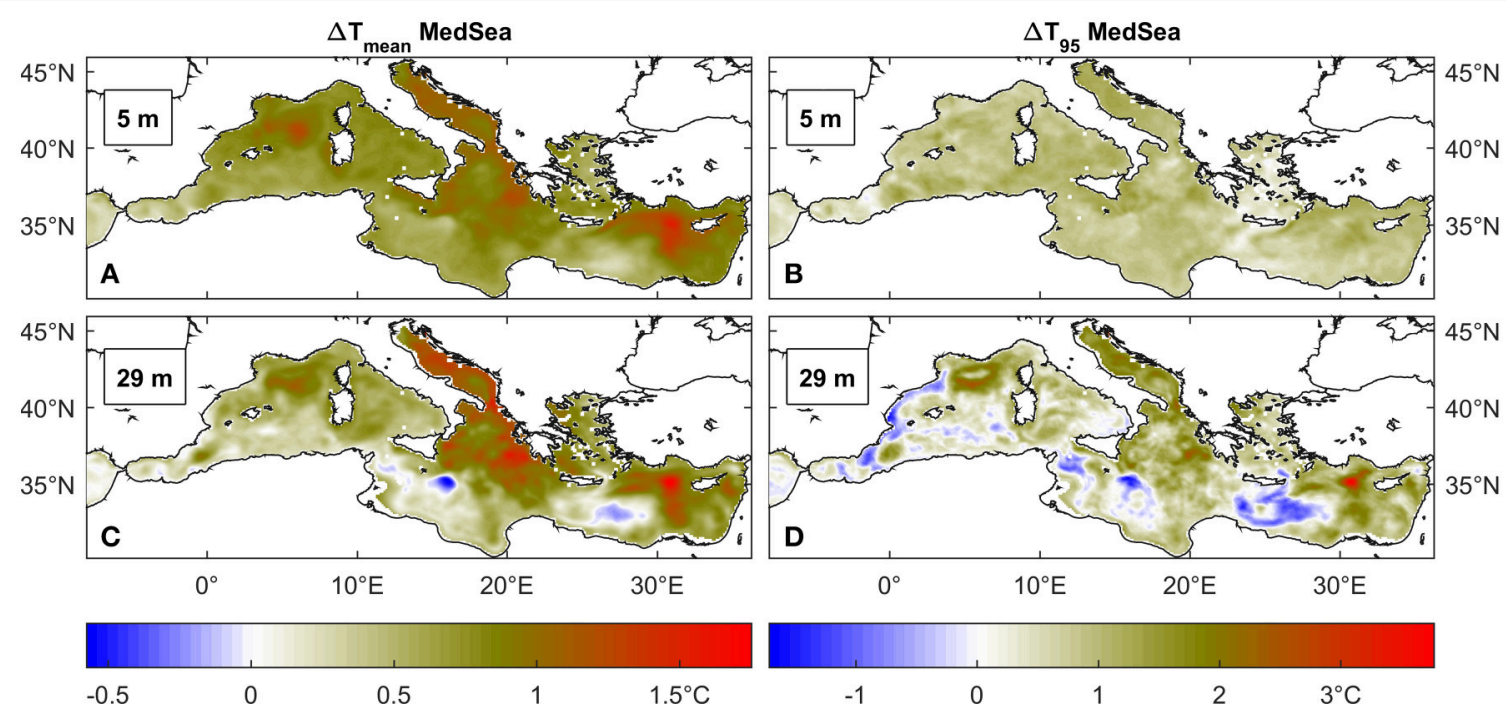

FIGURE 2 | Average (A,C) and 95 percentile (B,D) temperature $\left({ }^{\circ} \mathrm{C}\right)$ difference between 2041 and 2050 and $2001-2010$ time windows across the Mediterranean Sea at two depths, respectively 5 and $29 \mathrm{~m}$ depth.
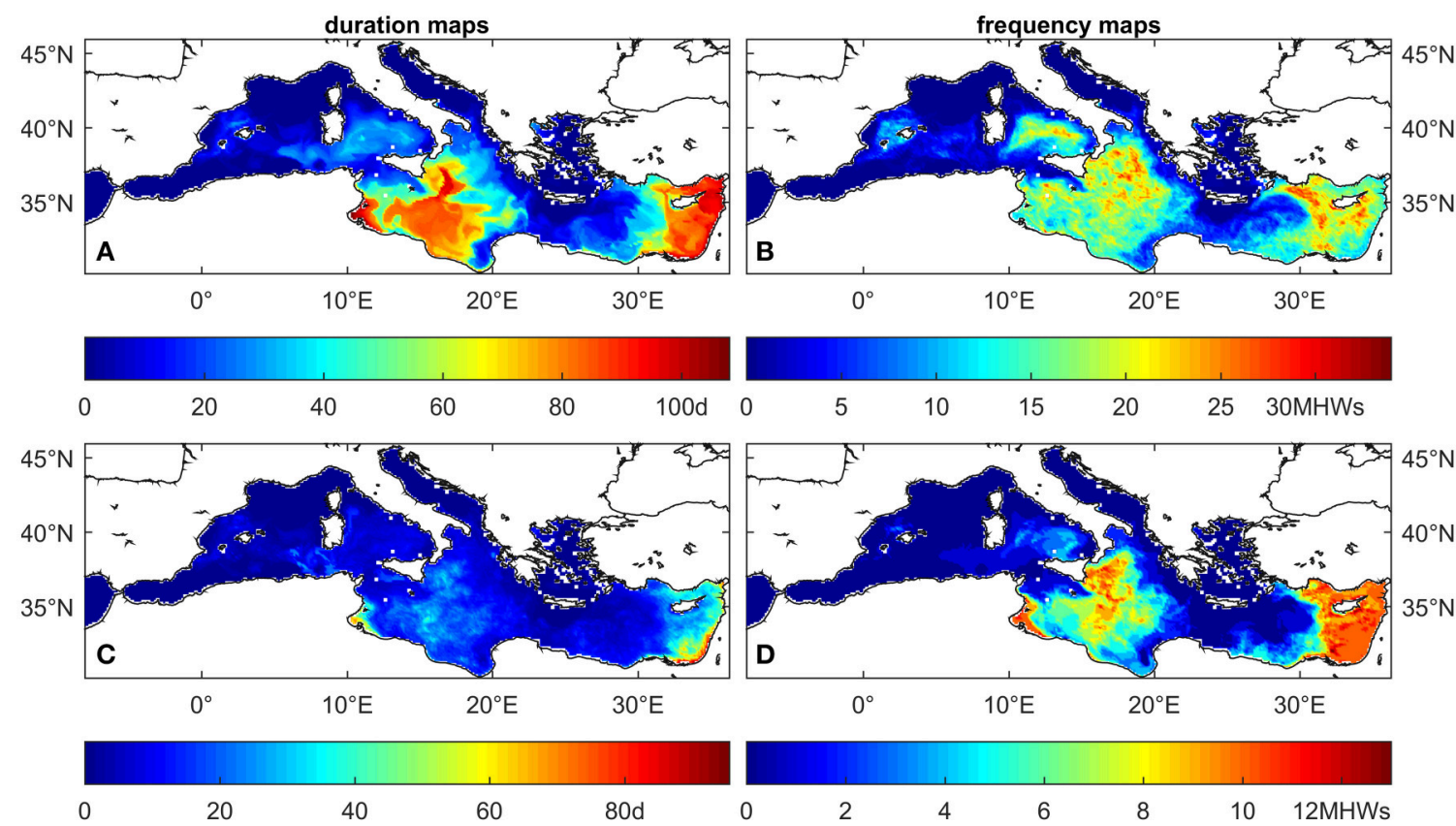

FIGURE 3 | Examples of the maps that constitute the hazard layer for reference temperature $\mathrm{T}^{\star}=28^{\circ} \mathrm{C}$ at $5 \mathrm{~m}$ depth for the reference period 2001-2010. (A) maximal duration of all MHWs with $T \geq T^{\star}$, (B) number of MHWs (frequency) with $T \geq T^{\star}$, (C) average duration of all $M H W s$ with $T \geq T^{\star}$, (D) frequency of $\mathrm{MHWs}$ with $\mathrm{T} \geq \mathrm{T}^{*}$ and duration $\geq 15$ days.

the occurrence of anomalies to substantially increase (Figure S1.1). Though this is evident along Spanish, French and Italian coasts only up to $20 \mathrm{~m}$ depth, which is about the current upper distribution limit of C. rubrum. Stress events penetrate deeper (up to $30 \mathrm{~m}$ ) in the central part of NW Mediterranean, including the Spanish coast, Balearic Islands and coasts of Sardinia and Sicily.

\section{Events with Temperature Exceeding $28^{\circ} \mathrm{C}$ in NW Mediterranean}

The maps in Figures 6A,C,E,G show that, under present conditions, there are just few occurrences of moderate duration exposure anomalies in sites of Western Mediterranean and Adriatic Sea where mussel farming is common (Spanish and French Coasts, Northern Adriatic). Nevertheless, an area 


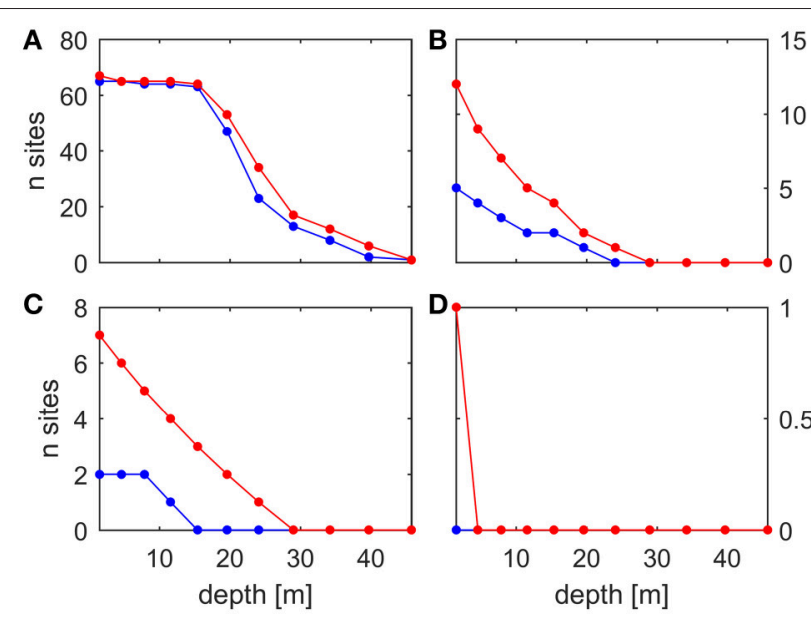

FIGURE 4 | Present (blue) and future (red) number of sites among the considered presence records where each MHW occurred at least once. (A): $25^{\circ} \mathrm{C} \times 12$ days threshold, presence records for $\mathrm{C}$. rubrum. (B) $28^{\circ} \mathrm{C} \times 15$ days threshold, presence records for $M$. galloprovincialis. (C) $28^{\circ} \mathrm{C} \times 30$ days threshold, presence records for $M$. galloprovincialis. (D) $30^{\circ} \mathrm{C} \times 20$ days threshold, presence records for $M$. galloprovincialis. For the sake of completeness, we include all of the depth levels, so the very shallow data points in (A) are not actually relevant for $C$. rubrum and the deep data points in (B-D) are not actually relevant for $M$. galloprovincialis.

interested by such anomalies is present at very shallow depths in the Balearic Sea not far from the location where Ramón et al. (2007) observed mussels mortality. This same area includes the Balearic Islands where Marbà and Duarte (2010) observed $P$. oceanica mortality. Moderate duration exposure anomalies instead are projected along the coasts of Southern Italy and in the Aegean Sea also in sites where mussels are farmed and where in fact mortality episodes are known to have occurred (Rodrigues et al., 2015).

Long duration exposure anomalies instead are not detected near mussel farming areas under present conditions (Figures 6A,C,E,G), except for the Thermakios gulf at very shallow depths (2 m).

Conversely, under future conditions (Figures 4C, 6B,D,F,H) the areas interested by long duration exposure expand to include a large portion of the Spanish coast, most of southern Italy (including the Gulf of Taranto), the Northern Adriatic and the Thermakios gulf, up to at least $12 \mathrm{~m}$ depths at most locations. The same happens with areas characterized by moderate duration exposure that expand along the Spanish coast, Central Italy, Eastern Adriatic and Western Aegean Sea. The projection of MedSea dataset also indicates a considerable increase in events frequency (Figures S1.2, S1.3), especially for moderate duration exposure events.

\section{Events with Temperature Exceeding $30^{\circ} \mathrm{C}$ in the Mediterranean}

Temperature levels $\geq 30^{\circ} \mathrm{C}$ are uncommon in the Mediterranean Sea under present conditions (Figures 7A,C,E,G), even at the surface, except for some coastal areas of Tunisia, Egypt and Israel and in the Ionian Basin south-east of Sicily. The threshold duration of 20 days, indicated as lethal for M. galloprovincialis, appears not to concern the regions where this species is cultivated (Figure 4D), namely the Western Basin, Adriatic and Greek seas, even under future conditions. However, this threshold is consistently exceeded under future conditions (Figures 7B,D,F,H) along the eastern coasts of Sicily and Tunisia up to a depth of about $12 \mathrm{~m}$. In particular, the largest occurrence of such events is seen in coastal areas of the Levantine basin, from southeast Turkey to Egypt, and around Cyprus up to depths of around $40 \mathrm{~m}$ (not shown). Events frequency is also predicted to increase (Figure S1.4).

\section{DISCUSSION}

In this paper we exploited the MedSea temperature dataset, originated from a high resolution physical model (see Section Projection Data and Temperature Regimes Analysis), to produce 3D maps of thermal thresholds exceedances under present (2001-2010) and future (2041-2050) climate conditions, with the aim of quantifying the change in duration, spatial extent and depth penetration of thermal anomalies that were found to be associated with low motility organism's mortality. Model output can be used in combination with information on species thermal limits, to produce forecasts related to the impacts of MHWs on marine organisms over the whole Mediterranean Sea. We presented hazard maps for the thermal thresholds of 25, 28, and $30^{\circ} \mathrm{C}$ that, according to published studies, upon sufficiently prolonged exposure (as detailed in Materials and Methods), affect the survival of (for example) the red coral C. rubrum, the mussel M. galloprovincialis and the seagrass $P$. oceanica. Our results indicate that thermal anomalies comparable to those that lead to mortality effects for our test species are expected to increase in duration, frequency and spatial extent in the near future, with likely adverse consequences on organisms with low motility living in shallow or relatively shallow waters.

Maps related to other thresholds in the range $20-32^{\circ} \mathrm{C}$ can be found in the Supplementary Material S2, and their analysis support similar conclusions. The dataset we provide can be used, in combination with information on species thermal limits, to assess expected impacts on marine organisms from all the Mediterranean.

\section{Considerations on the Expected Impacts on C. rubrum and Coralligenous Communities}

Our results suggest that summer heat waves of magnitude capable to cause mortality in C. rubrum as well as in many other coralligenous species may become commonplace in Western Mediterranean in the near future. Consequently, it might be expected that there will be repeated and extensive mass mortality episodes, possibly impacting at the community level up to severe reduction or local extinction (extirpation) of shallow coral banks.

Many studies suggest that coralligenous communities are not completely extirpated by single harmful events and exhibit recovery capabilities. Bramanti et al. (2005) observed a reduction in recruitment and survival rates, but not complete nullification, 


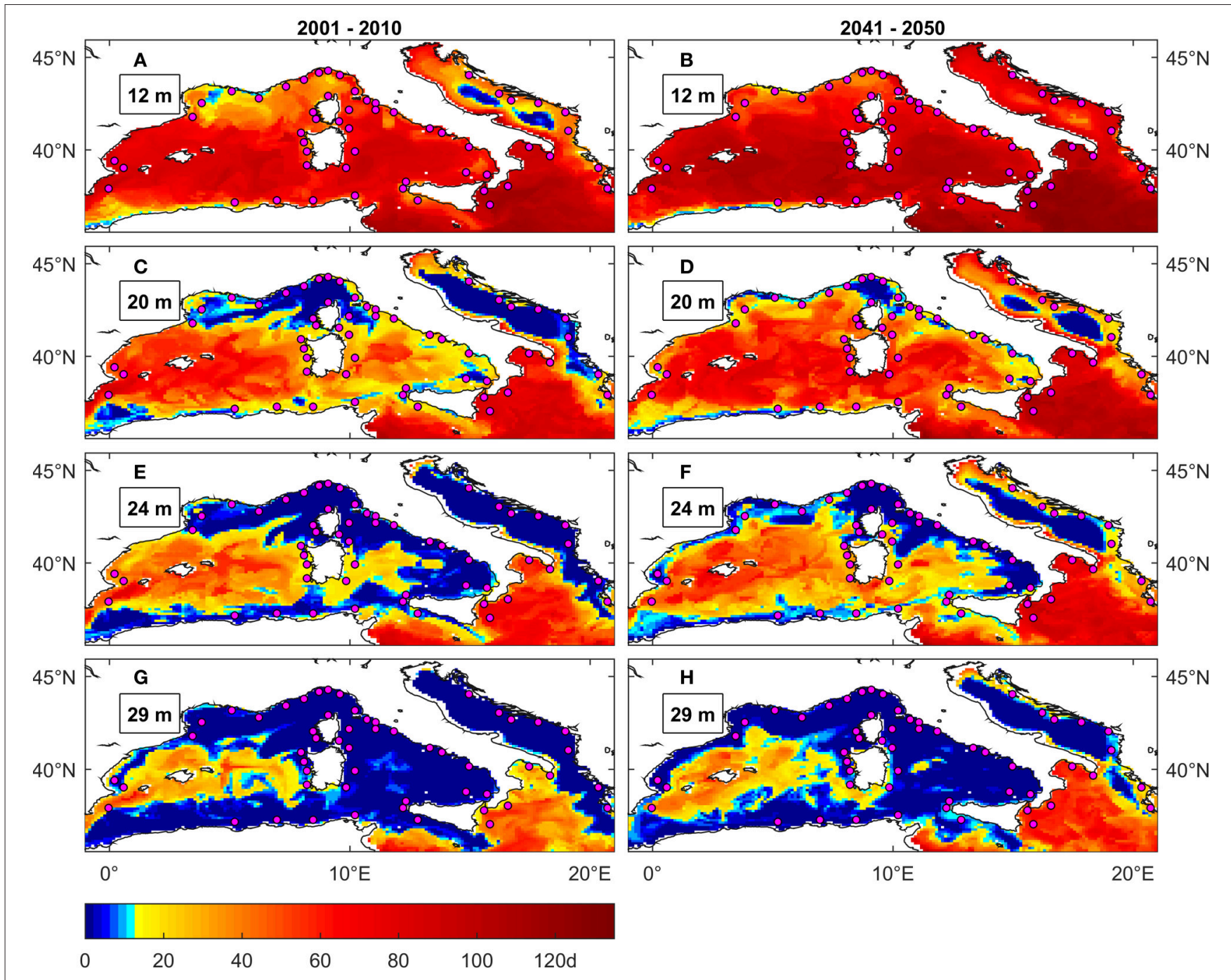

FIGURE 5 | Maximal number of consecutive days above $25^{\circ} \mathrm{C}$ in NW Mediterranean and Adriatic under present (A,C,E,G) and future (B,D,F,H) conditions at different depths. The colormap is modified to highlight the duration threshold of 12 days that is the average of the values ( 9 and 14 days) identified in Torrents et al. (2008) as critical for C. rubrum deep and shallow populations survival respectively. Magenta circles are C. rubrum presence records (Harmelin, 2006).

in juvenile C. rubrum colonies during the 1999 mass mortality event, and the effects were evident only at $25 \mathrm{~m}$ depth and no longer observable at $35 \mathrm{~m}$. Cupido et al. $(2009,2008)$ reported a significant recovery in gorgonian populations following the 2003 mass mortality with a four-fold increase in recruitment. On the other hand, evidence suggests that the largest colonies, which are of paramount importance for recolonization phenomena because of their substantial contribution to populations reproductive output (Santangelo et al., 2003), also display the highest damage rate during mass mortality events (Garrabou et al., 2001; Cupido et al., 2008). Additionally, modeling results on C. rubrum population dynamics (Santangelo et al., 2007, 2012) pointed out that, despite of recolonization phenomena, if mortality events are frequent enough (the authors estimate one occurrence every 2-4 years, depending on the magnitude of the event) populations may no longer be able to recover and will go locally extinct.
Our results point at a general increase in frequency, intensity and depth penetration of marine heat waves in the forthcoming decades. Even though these effects are confined to the upper portion of the water column, they still would affect C. rubrum populations and coralligenous communities living above $\sim 30 \mathrm{~m}$ depth. In the case of C. rubrum these populations are already severely depleted because of overharvesting (Tsounis et al., 2007; Santangelo and Bramanti, 2010; Cau et al., 2016) and are thus less resilient. The most likely outcome of the increase in heat waves therefore is a deepening of the survival horizon for C. rubrum and, possibly, other coralligenous macroinvertebrates. The same conclusion has been derived also for the closely related species $P$. clavata, in Bensoussan et al. (2013) with a similar methodology. In fact, even though the exposure thresholds used in this study were determined for C. rubrum, the same mortality events similarly affected several coralligenous species (Garrabou et al., 

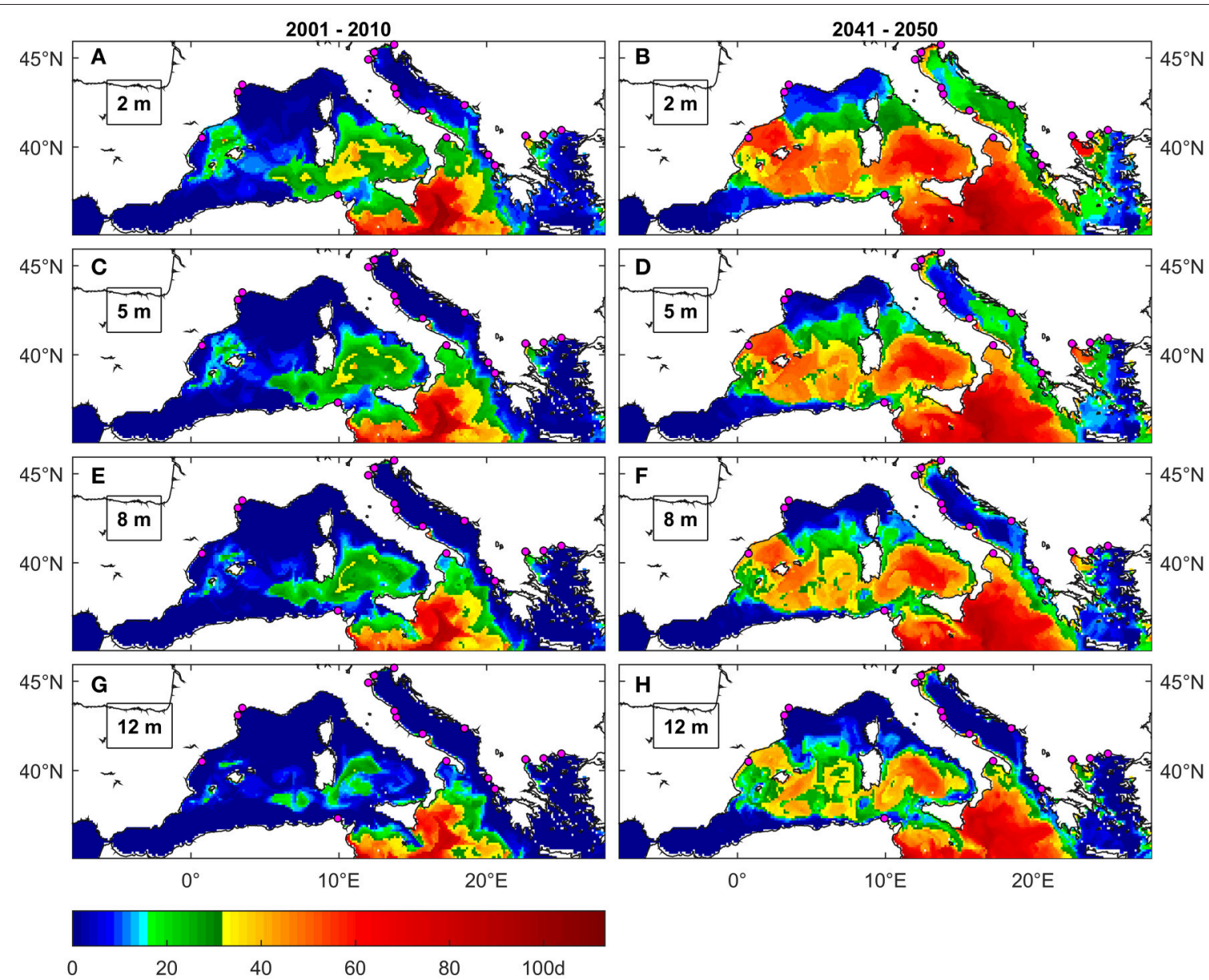

FIGURE 6 | Maximal number of consecutive days above $\mathbf{2 8}^{\circ} \mathbf{C}$ under present $\mathbf{( A , C , E , G )}$ and future (B,D,F,H) conditions at different depths. The colormap is modified to highlight the thresholds of 15 (shades of green) and 30 days (yellow to red) that were reported respectively as lethal for mussels cultured in Spain (Ramón et al., 2007) and partially lethal for mussels cultured in the Aegean (Anestis et al., 2007). Magenta dots are locations of mussel farming facilities (Rodrigues et al., 2015).

2009), pointing at comparable thermal limits. This instance is also supported by a comparison of thermotolerance thresholds estimated for similar gorgonian species (P. clavata, E. singolaris, Crisci et al., 2011 and references therein). Also in this case, mortality events might cause, besides ecological damages, a direct economic cost, due to the impacts on scuba diving tourism (Rodrigues et al., 2013).

\section{Considerations on the Expected Impacts on M. galloprovincialis and Aquaculture Activities}

M. galloprovincialis is regarded as a resistant species: it commonly grows in coastal waters with high nutrient load and in enclosed or semi-enclosed systems, which are characterized by high variability, and it can even tolerate, in the case of intertidal mussels, short (hours) exposure to air temperature higher than $30^{\circ} \mathrm{C}$ (Sarà et al., 2011).

Also the difference in mortality response observed under similar conditions in the Western (Ramón et al., 2007; Gazeau et al., 2014) vs. Eastern (Anestis et al., 2007, 2010)
Mediterranean marine regions suggests that this species has the capability to adapt/acclimate to different thermal regimes.

Nonetheless, the thermal conditions of the Mediterranean appear to be close to the upper limit for this species: temperature levels of $25^{\circ} \mathrm{C}$, which are commonly reached during summer over large areas of the Mediterranean, especially in shallow water coastal systems, have been identified, at best, as an upper limit for mussels normal physiological activities (Anestis et al., 2007, 2010; Gazeau et al., 2014), at worst to induce a drastic increase in mortality rates (Gazeau et al., 2014). This clearly indicates that the Mediterranean mussels already live close to their thermal limits. In fact, the most of the production of Spain takes place in the cooler Atlantic waters, where this species performs better and grows to a larger size. Also, according to Rodrigues et al. (2015), 13 out of a total of 16 surveyed mollusk production sites distributed across all the Mediterranean did experience difficulties in recent years (including mortality episodes) as a consequence of summery heat waves.

Moreover, in many cases shellfish production sites are located within bay or lagoon systems that are both likely to experience 

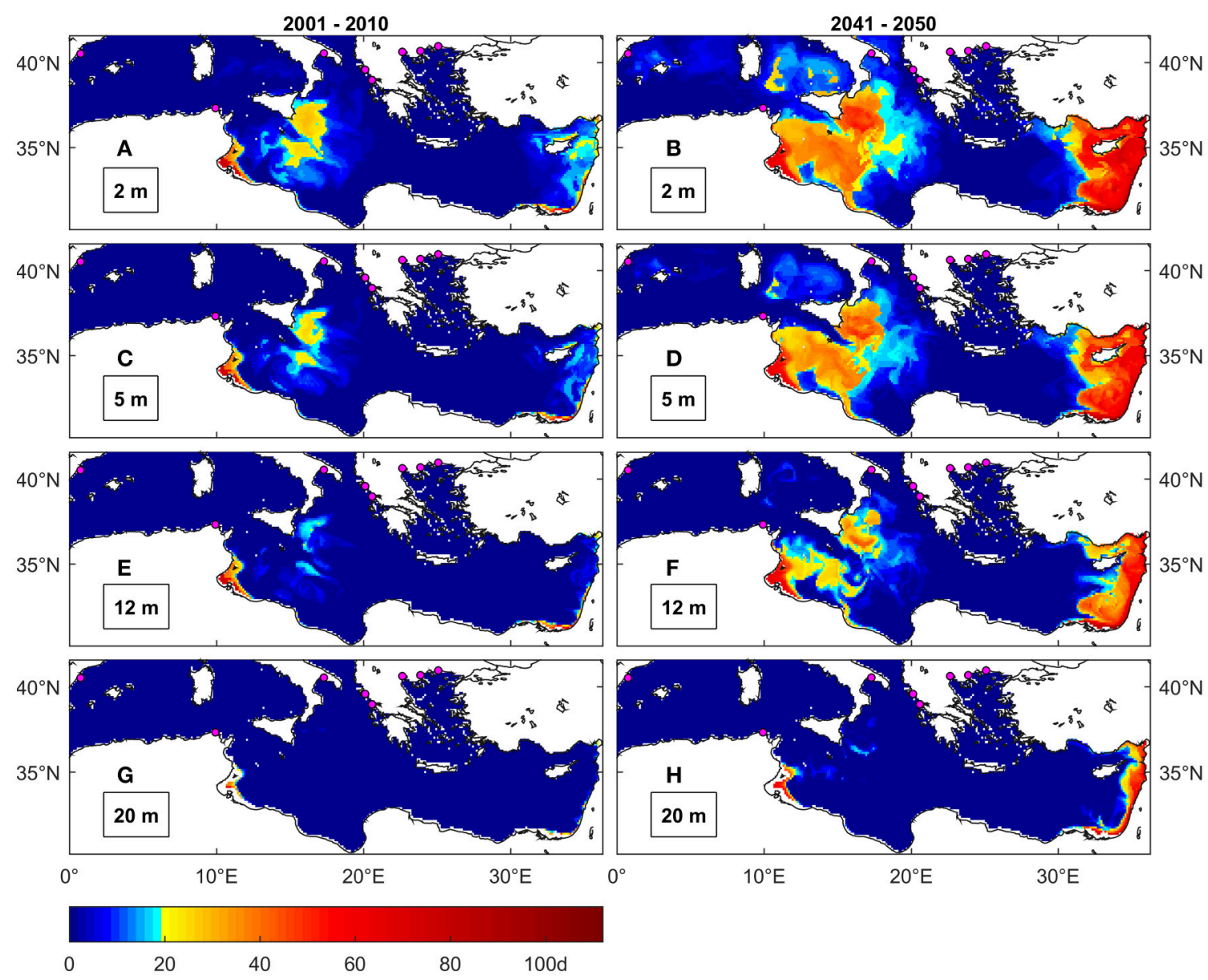

FIGURE 7 | Maximal number of consecutive days above $\mathbf{3 0}{ }^{\circ} \mathbf{C}$ under present $\mathbf{( A , C , E , G )}$ and future $\mathbf{( B , D , F , H ) ~ c o n d i t i o n s ~ a t ~ d i f f e r e n t ~ d e p t h s . ~ T h e ~ c o l o r m a p ~ i s ~}$ modified to highlight the threshold of 20 days identified by Anestis et al. (2007) as lethal for M. galloprovincialis from the Thermakios gulf (Greece). Magenta dots are locations of mussel farming facilities (Rodrigues et al., 2015).

warmer summer temperatures than the open sea, and vulnerable to other stressors such as lack of oxygen. The latter conditions are not accounted by the MedSea dataset, whose projections are hence to be considered a conservative estimate; but still, our results show that an increase in frequency and intensity of MHWs will likely cause a sensible reduction of the number of suitable farming sites; mitigation measures might be needed, such as substituting local seeds with others with higher thermotolerance and/or, where possible, moving the cultivation to deeper waters. However, both options would reflect on operating costs.

\section{Considerations on the Expected Impacts on P. oceanica Meadows and Tropicalization of the Mediterranean}

In agreement with Jordà et al. (2012), our projections suggest an uncertain future $P$. oceanica meadows, which today represent the first hotspot of biodiversity in the Mediterranean (Boudouresque, 2004). This conclusion is especially relevant for the area around the Balearic Islands. In fact, all the data we considered for $P$. oceanica thermotolerance where assessed there, and this area appears as a hotspot for future occurrence of MHWs in Western Mediterranean.

Finally, our projections support that the severest thermal extremes $\left(30^{\circ} \mathrm{C}\right.$ threshold map, Figure 7$)$ will affect large areas of the Ionian and Levantine Basins, especially the easternmost coasts from Southern Turkey to Egypt. This adds to the overwhelming evidence that a trend in tropicalization (Bianchi and Morri, 2003; Bianchi, 2007) is affecting large parts of the Mediterranean Sea even under current conditions.

\section{Issues Concerning the Assessment of MHWs Impacts on Marine Organisms and Current Knowledge Gaps}

The comparison of thermal regimes with species thermotolerance can provide a first order approximation of potential impacts of climate change on one or more species that is likely to be (at least) qualitatively robust. However, it is appropriate to remember that since results depend on the identification of physiological thresholds, they are bound to be affected by uncertainty and simplifications. Thermal tolerance 
thresholds of a given species might depend on its biological history, change across different areas, exhibit individual variability, and be biased by the experimental conditions in which they were determined. Thus, a straightforward extrapolation of threshold values might not always provide accurate results.

As an example, the thermo-tolerance thresholds for coralligenous species that are retrievable in the literature were all determined for specimen collected in the northern part of Western Mediterranean (Crisci et al., 2011 and references therein), which is characterized by cooler average temperatures. Populations from such region might thus be adapted to cooler temperatures and be more sensitive to warming (Torrents et al., 2008) than specimen in southern areas. Those spatial differences could be easily accommodated by using different thresholds for different areas, if the biological information were available, or by linking the threshold to the average temperature of the area (Solidoro et al., 2010). However, currently there is not enough information to do so. We underline that in order to produce accurate and reliable impact assessments it is of great importance to understand how thermotolerance limits change across thermal gradients. To thoroughly characterize the thermotolerance of even a small part of Mediterranean species is such a demanding effort as to appear unrealistic, but this may not be the case. In fact, whereas a single mass mortality threshold for species and populations does not exist (Garrabou et al., 2001, 2009; Torrents et al., 2008), the amount of different species that were concomitantly affected during the same events (Garrabou et al., 2009) and a comparison of laboratory determined thermal thresholds (compiled in Crisci et al., 2011) suggest that thermal limits for species (and/or populations) occupying similar ecological niches (i.e., adapted to similar environmental conditions) are reasonably similar. The estimated response for a sufficiently representative test species could thus serve as a proxy for similar species that are adapted to analogous environmental conditions.

Secondly, populations' response will also depend on acclimation, adaptation and recolonization phenomena. Haguenauer et al. (2013) and Torrents et al. (2008) found strong evidence for thermal adaptation in C. rubrum populations even on small spatial scales. Organisms, though, cannot always adapt to every condition. In fact, Haguenauer et al. (2013) also identified a trade-off between thermal adaptation and general metabolism in C. rubrum and concluded that acclimation beyond a certain threshold can be deleterious for fitness. In addition, Rodolfo-Metalpa et al. (2014) found little evidence of variation in overall thermal tolerance in specimen of the stony coral Oculina Patagonica from Mediterranean sites characterized by $>3^{\circ} \mathrm{C}$ variation in mean maximum annual temperature.

Several studies highlight that ectothermic species, such as corals or mussels, have the capability to tolerate exposure to temperatures close to the their upper limits, and even to adapt their thermal limits (Buckley et al., 2001; Middlebrook et al., 2008). However, it must be considered that acclimation might not be very effective for episodic exposures to extreme conditions, and thermal acclimation limits anyway exist. In fact, other studies reported a decrease in tolerance to high temperature after repeated exposures (Jones et al., 2009), and raised concerns about the capability of marine organisms to cope with a trend of increasing frequency of heat wave events. Also in this case, however, the knowledge required for a proper parameterization of these processes, at least to the best of our knowledge, is not available yet.

One final aspect that complicates the assessment of future species distribution is that species potential and realized niches often differ, also due to sub-lethal effects on biotic processes like recruitment and competition (Fordham, 2015; Mellin et al., 2016). Poor recruitment from neighboring populations, loss of competitive ability, newcomer species and predatory pressure can impair the recovery of severely depleted populations even in the absence of further climate stressors (e.g., Tagliarolo and McQuaid, 2015; Wernberg et al., 2016). So, while MHW occurrence may serve to identify potential spatial distribution limits (potential niche), it may fail to capture other factors that concur in limiting a species distribution.

\section{AUTHOR CONTRIBUTIONS}

All authors contributed equally to this work. TL retrieved temperature datasets and supported the seawater temperature assessment, GG post-processed temperature datasets and produced the hazard model, CS developed the concept, supervised the research. All authors discussed the results and implications and contributed to the manuscript writing at all stages.

\section{FUNDING}

The research reported in this work was supported by MEDSEA and PERSEUS projects and by OGS and CINECA under HPCTRES program award number 2015-05. Publication fees were covered by OpenAIRE-FP7-Post-Grant-OA-Pilot.

\section{ACKNOWLEDGMENTS}

We thank Paolo Lazzari, Giorgio Bolzon, Donata Melaku Canu, and Marcello Vichi, for technical help, discussion and suggestions.

\section{SUPPLEMENTARY MATERIAL}

The Supplementary Material for this article can be found online at: http://journal.frontiersin.org/article/10.3389/fmars. 2017.00136/full\#supplementary-material 


\section{REFERENCES}

Anestis, A., Lazou, A., Pörtner, H. O., and Michaelidis, B. (2007). Behavioral, metabolic, and molecular stress responses of marine bivalve Mytilus galloprovincialis during long-term acclimation at increasing ambient temperature. Am. J. Physiol. Integr. Comp. Physiol. 293, R911-R921. doi: 10.1152/ajpregu.00124.2007

Anestis, A., Pörtner, H. O., Karagiannis, D., Angelidis, P., Staikou, A., and Michaelidis, B. (2010). Response of Mytilus galloprovincialis (L.) to increasing seawater temperature and to marteliosis: metabolic and physiological parameters. Comp. Biochem. Physiol. A Mol. Integr. Physiol. 156, 57-66. doi: $10.1016 /$ j.cbpa.2009.12.018

Ballesteros, E. (2006). Mediterranean coralligenous assemblages: a synthesis of present knowledge. Oceanogr. Mar. Biol. An Annu. Rev. 44, 123-195. doi: 10.1201/9781420006391.ch4

Bally, M., and Garrabou, J. (2007). Thermodependent bacterial pathogens and mass mortalities in temperate benthic communities: a new case of emerging disease linked to climate change. Glob. Chang. Biol. 13, 2078-2088. doi: 10.1111/j.1365-2486.2007.01423.x

Bell, G. (2012). Evolutionary rescue and the limits of adaptation. Philos. Trans. $R$. Soc. Lond. B. Biol. Sci. 368:20120080. doi: 10.1098/rstb.2012.0080

Bennett, S., Wernberg, T., Arackal Joy, B., de Bettignies, T., and Campbell, A. H. (2015). Central and rear-edge populations can be equally vulnerable to warming. Nat. Commun. 6:10280. doi: 10.1038/ncomms10280

Bensoussan, N., Pairaud, I. L., Garreau, P., Somot, S., and Garrabou, J. (2013). "Multidisciplinary approach to assess potential risk of mortality of benthic ecosystems facing climate change in the NW Mediterranean Sea," in Oceans - San Diego (San Diego, CA: IEEE).

Bensoussan, N., Romano, J. C., Harmelin, J. G., and Garrabou, J. (2010). High resolution characterization of northwest Mediterranean coastal waters thermal regimes: to better understand responses of benthic communities to climate change. Estuar. Coast. Shelf Sci. 87, 431-441. doi: 10.1016/j.ecss.2010.01.008

Bianchi, C., and Morri, C. (2003). Global sea warming and "tropicalization" of the Mediterranean Sea: biogeographic and ecological aspects. Biogeographia XXIV, 319-329. doi: 10.21426/b6110129

Bianchi, C. N. (2007). Biodiversity issues for the forthcoming tropical Mediterranean Sea. Dev. Hydrobiol. 193, 7-21. doi: 10.1007/978-1-40206156-1_1

Boudouresque, C.-F. (2004). Marine biodiversity in the mediterranean; status of species, populations and communities. Trav. Sci. du Parc Natl. PortCros 20, 97-146. Available online at: http://www.portcrosparcnational. fr/Documentations/Marine-biodiversity-in-the-mediterranean-status- ofspicies-populations-and-communities

Bramanti, L., Magagnini, G., De Maio, L., and Santangelo, G. (2005). Recruitment, early survival and growth of the Mediterranean red coral Corallium rubrum (L 1758), a 4-year study. J. Exp. Mar. Bio. Ecol. 314, 69-78. doi: 10.1016/j.jembe.2004.08.029

Buckley, B. A., Owen, M. E., and Hofmann, G. E. (2001). Adjusting the thermostat: the threshold induction temperature for the heat-shock response in intertidal mussels (genus Mytilus) changes as a function of thermal history. J. Exp. Biol. 204, 3571-3579. Available online at: http://jeb.biologists.org/content/204/20/ 3571

Cau, A., Bramanti, L., Cannas, R., Follesa, M. C., Angiolillo, M., Canese, S., et al. (2016). Habitat constraints and self-thinning shape Mediterranean red coral deep population structure: implications for conservation practice. Sci. Rep. 6:23322. doi: 10.1038/srep23322

Coma, R., Ribes, M., Serrano, E., Jiménez, E., Salat, J., and Pascual, J. (2009). Global warming-enhanced stratification and mass mortality events in the Mediterranean. Proc. Natl. Acad. Sci. U.S.A. 106, 6176-6181. doi: 10.1073/pnas.0805801106

Cossarini, G., Lazzari, P., and Solidoro, C. (2015). Spatiotemporal variability of alkalinity in the Mediterranean Sea. Biogeosciences 12, 1647-1658. doi: 10.5194/bg-12-1647-2015

Costantini, F., Taviani, M., Remia, A., Pintus, E., Schembri, P. J., and Abbiati, M. (2010). Deep-water Corallium rubrum (L., 1758) from the Mediterranean Sea: preliminary genetic characterisation. Mar. Ecol. 31, 261-269. doi: 10.1111/j.1439-0485.2009.00333.x

Crisci, C., Bensoussan, N., Romano, J. C., and Garrabou, J. (2011). Temperature anomalies and mortality events in marine communities: insights on factors behind differential mortality impacts in the NW Mediterranean. PLoS ONE 6:e23814. doi: 10.1371/journal.pone.0023814

Cupido, R., Cocito, S., Barsanti, M., Sgorbini, S., Peirano, A., and Santangelo, G. (2009). Unexpected long-term population dynamics in a canopy-forming gorgonian coral following mass mortality. Mar. Ecol. Prog. Ser. 394, 195-200. doi: 10.3354/meps08260

Cupido, R., Cocito, S., Sgorbini, S., Bordone, A., and Santangelo, G. (2008). Response of a gorgonian (Paramuricea clavata) population to mortality events: recovery or loss? Aquat. Conserv. Mar. Freshw. Ecosyst. 18, 984-992. doi: $10.1002 /$ aqc. 904

Cushman-Roisin, B., Gačić, M., Poulain, P.-M., and Artegiani, A. (2001). Physical Oceanography of the Adriatic Sea. Past, Present and Future. Springer Netherlands. doi: 10.1007/978-94-015-9819-4

Déqué, M., Rowell, D. P., Lüthi, D., Giorgi, F., Christensen, J. H., Rockel, B., et al. (2007). An intercomparison of regional climate simulations for Europe: assessing uncertainties in model projections. Clim. Change 81, 53-70. doi: $10.1007 / \mathrm{s} 10584-006-9228-\mathrm{x}$

Diffenbaugh, N. S., Pal, J. S., Giorgi, F., and Gao, X. (2007). Heat stress intensification in the Mediterranean climate change hotspot. Geophys. Res. Lett. 34, 1-6. doi: 10.1029/2007GL030000

FAO (2010). FISHSTAT Plus: Universal Software for Fishery Statistical Time Series. Rome: Food Agriculture Organization.

Fordham, D. A. (2015). Mesocosms reveal ecological surprises from climate change. PLoS Biol. 13:e1002323. doi: 10.1371/journal.pbio.1002323

Garrabou, J., Coma, R., Bensoussan, N., Bally, M., Chevaldonné, P., Cigliano, M., et al. (2009). Mass mortality in Northwestern Mediterranean rocky benthic communities: effects of the 2003 heat wave. Glob. Chang. Biol. 15, 1090-1103. doi: 10.1111/j.1365-2486.2008.01823.x

Garrabou, J., Perez, T., Sartoretto, S., and Harmelin, J. G. (2001). Mass mortality event in red coral Corallium rubrum populations in the Provence region (France, NW Mediterranean). Mar. Ecol. Prog. Ser. 217, 263-272. doi: $10.3354 /$ meps 217263

Gazeau, F., Alliouane, S., Bock, C., Bramanti, L., López Correa, M., Gentile, M., et al. (2014). Impact of ocean acidification and warming on the Mediterranean mussel (Mytilus galloprovincialis). Front. Mar. Sci. 1:62. doi: $10.3389 /$ fmars.2014.00062

Great Barrier Reef Marine Park Authority (2016). Coral Bleaching Event on the Great Barrier Reef. Nterim Report: 2016, Townsville, QLD.

Gualdi, S., Somot, S., Li, L., Artale, V., Adani, M., Bellucci, A., et al. (2013). The circe simulations: regional climate change projections with realistic representation of the mediterranean sea. Bull. Am. Meteorol. Soc. 94, 65-81. doi: 10.1175/BAMS-D-11-00136.1

Haguenauer, A., Zuberer, F., Ledoux, J. B., and Aurelle, D. (2013). Adaptive abilities of the Mediterranean red coral Corallium rubrum in a heterogeneous and changing environment: from population to functional genetics. J. Exp. Mar. Biol. Ecol. 449, 349-357. doi: 10.1016/j.jembe.2013.10.010

Harmelin, J.-G. (2006). L'or Rouge: un Objet de Fascination. Available online at: http://www.futura-sciences.com/magazines/nature/infos/dossiers/d/fauneor-rouge- objetfascination-\%0A606/

Hobday, A. J., Alexander, L. V., Perkins, S. E., Smale, D. A., Straub, S. C., Oliver, E. C. J., et al. (2016). A hierarchical approach to defining marine heatwaves. Prog. Oceanogr. 141, 227-238. doi: 10.1016/j.pocean.2015.12.014

Huete-Stauffer, C., Vielmini, I., Palma, M., Navone, A., Panzalis, P., Vezzulli, L., et al. (2011). Paramuricea clavata (Anthozoa, Octocorallia) loss in the marine protected area of Tavolara (Sardinia, Italy) due to a mass mortality event. Mar. Ecol. 32, 107-116. doi: 10.1111/j.1439-0485.2011.00429.x

IPCS (2004). IPCS Risk Assessment Terminology. (Geneva: World Health Organization), 117. Available online at: http://apps.who.int/iris/handle/10665/ 42908

Jones, S. J., Mieszkowska, N., and Wethey, D. S. (2009). Linking thermal tolerances and biogeography: Mytilus edulis (L.) at its southern limit on the east coast of the United States. Biol. Bull. 217, 73-85. doi: 10.1086/BBLv217n1p73

Jordà, G., Marbà, N., and Duarte, C. M. (2012). Mediterranean seagrass vulnerable to regional climate warming. Nat. Clim. Change 2, 821-824. doi: $10.1038 /$ nclimate 1533

Lazzari, P., Solidoro, C., Salon, S., and Bolzon, G. (2016). Spatial variability of phosphate and nitrate in the Mediterranean Sea: a modeling approach. Deep Sea Res. Part I Oceanogr. Res. Pap. 108, 39-52. doi: 10.1016/j.dsr.2015. 12.006 
Lovato, T., Vichi, M., and Oddo, P. (2013). High resolution simulations of Mediterranean Sea physical oceanography under current and scenario climate conditions: model description, assessment and scenario analysis. CMCC Res. Pap. 1-26. doi: 10.2139/ssrn.2637861

Madec, G. (2008). NEMO Ocean Engine. Note du Pole de Modelisation Institute Pierre-Simone Lapalce No. 27 (IPSL), France.

Marbà, N., and Duarte, C. M. (2010). Mediterranean warming triggers seagrass (Posidonia oceanica) shoot mortality. Glob. Change Biol. 16, 2366-2375. doi: 10.1111/j.1365-2486.2009.02130.x

Marbà, N., Jordà, G., Agustí, S., Girard, C., and Duarte, C. M. (2015). Footprints of climate change on Mediterranean Sea biota. Front. Mar. Sci. 2:56. doi: $10.3389 /$ fmars.2015.00056

Martin, Y., Bonnefont, J. L., and Chancerelle, L. (2002). Gorgonians mass mortality during the 1999 late summer in French Mediterranean coastal waters: the bacterial hypothesis. Water Res. 36, 779-782. doi: 10.1016/S0043-1354(01) 00251-2

Mellin, C., Lurgi, M., Matthews, S., MacNeil, M. A., Caley, M. J., Bax, N., et al. (2016). Forecasting marine invasions under climate change: biotic interactions and demographic processes matter. Biol. Conserv. 204, 459-467. doi: 10.1016/j.biocon.2016.11.008

Middlebrook, R., Hoegh-Guldberg, O., and Leggat, W. (2008). The effect of thermal history on the susceptibility of reef-building corals to thermal stress. J. Exp. Biol. 211, 1050-1056. doi: 10.1242/jeb.013284

Oddo, P., Adani, M., Pinardi, N., Fratianni, C., Tonani, M., and Pettenuzzo, D. (2009). A nested atlantic-mediterranean sea general circulation model for operational forecasting. Ocean Sci. 5, 461-473. doi: 10.5194/os-5461-2009

Pairaud, I. L., Bensoussan, N., Garreau, P., Faure, V., and Garrabou, J. (2014). Impacts of climate change on coastal benthic ecosystems: assessing the current risk of mortality outbreaks associated with thermal stress in NW Mediterranean coastal areas Topical Collection on the 16th biennial workshop of the Joint Numerical Sea Modelli. Ocean Dyn. 64, 103-115. doi: 10.1007/s10236-013-0661-x

Perez, T., Garrabou, J., Sartoretto, S., Harmelin, J.-G., Francour, P., and Vacelet, J. (2000). Mortalité massive d'invertébrés marins: un événement sans précédent en Méditerranée nord-occidentale. Comp. Rendus l'Acad. des Sci. Ser. III Sci. la Vie 323, 853-865. doi: 10.1016/s0764-4469(00)01237-3

Ramón, M., Fernández, M., and Galimany, E. (2007). Development of mussel (Mytilus galloprovincialis) seed from two different origins in a semi-enclosed Mediterranean Bay (N.E. Spain). Aquaculture 264, 148-159. doi: 10.1016/j.aquaculture.2006.11.014

Rodolfo-Metalpa, R., Hoogenboom, M. O., Rottier, C., Ramos-Esplá, A., Baker, A. C., Fine, M., et al. (2014). Thermally tolerant corals have limited capacity to acclimatize to future warming. Glob. Chang. Biol. 20, 3036-3049. doi: $10.1111 /$ gcb.12571

Rodrigues, L. C., van den Bergh, J. C. J. M., and Ghermandi, A. (2013). Socioeconomic impacts of ocean acidification in the Mediterranean Sea. Mar. Policy 38, 447-456. doi: 10.1016/j.marpol.2012.07.005

Rodrigues, L. C., Van Den Bergh, J. C. J. M., Massa, F., Theodorou, J. A., Ziveri, P., and Gazeau, F. (2015). Sensitivity of Mediterranean bivalve mollusc aquaculture to climate change and ocean acidification: results from a producers' survey. J. Shellfish Res. 34, 1-16. doi: 10.2983/035.034.0341

Rossi, S., and Tsounis, G. (2007). Temporal and spatial variation in protein, carbohydrate, and lipid levels in Corallium rubrum (Anthozoa, Octocorallia). Mar. Biol. 152, 429-439. doi: 10.1007/s00227-007-0702-4

Rossi, S., Tsounis, G., Orejas, C., Padrón, T., Gili, J. M., Bramanti, L., et al. (2008). Survey of deep-dwelling red coral (Corallium rubrum) populations at Cap de Creus (NW Mediterranean). Mar. Biol. 154, 533-545. doi: 10.1007/s00227-008-0947-6

Ruti, P. M., Somot, S., Giorgi, F., Dubois, C., Flaounas, E., Obermann, A., et al. (2016). Med-CORDEX initiative for Mediterranean climate studies. Bull. Am. Meteorol. Soc. 97, 1187-1208. doi: 10.1175/BAMS-D-14-00176.1

Santangelo, G., and Bramanti, L. (2010). Quantifying the decline in Corallium rubrum populations. Mar. Ecol. Prog. Ser. 418, 295-297. doi: $10.3354 /$ meps08897

Santangelo, G., Bramanti, L., and Iannelli, M. (2007). Population dynamics and conservation biology of the over-exploited Mediterranean red coral. J. Theor. Biol. 244, 416-423. doi: 10.1016/j.jtbi.2006.08.027
Santangelo, G., Carletti, E., Maggi, E., and Bramanti, L. (2003). Reproduction and population sexual structure of the overexploited Mediterranean red coral Corallium rubrum. Mar. Ecol. Prog. Ser. 248, 99-108. doi: 10.3354/meps248099

Santangelo, G., Cupido, R., Cocito, S., Bramanti, L., Tsounis, G., and Iannelli, M. (2012). "Demography of long-lived octocorals: survival and local extinction," in Proceedings 12th International Coral Reef Symposium, 9-13. Available online at: http://www.researchgate.net/publication/230868164_Demography_of_longlived_octocorals_survival_and_local_extinction/file/9fcfd50590521a4edb.pdf

Sarà, G., Kearney, M., and Helmuth, B. (2011). Combining heat-transfer and energy budget models to predict thermal stress in Mediterranean intertidal mussels. Chem. Ecol. 27, 135-145. doi: 10.1080/02757540.2011.552227

Scoccimarro, E., Gualdi, S., Bellucci, A., Sanna, A., Fogli, P. G., Manzini, E., et al. (2011). Effects of tropical cyclones on ocean heat transport in a high-resolution coupled general circulation model. J. Clim. 24, 4368-4384. doi: 10.1175/2011JCLI4104.1

Seneviratne, S. I., Donat, M. G., Mueller, B., and Alexander, L. V. (2014). No pause in the increase of hot temperature extremes. Nat. Clim. Change 4, 161-163. doi: $10.1038 /$ nclimate 2145

Smale, D. A., and Wernberg, T. (2013). Extreme climatic event drives range contraction of a habitat-forming species. Proc. Biol. Sci. 280:20122829. doi: $10.1098 / \mathrm{rspb} .2012 .2829$

Solidoro, C., Cossarini, G., Libralato, S., and Salon, S. (2010). Remarks on the redefinition of system boundaries and model parameterization for downscaling experiments. Prog. Oceanogr. 84, 134-137. doi: 10.1016/j.pocean.2009.09.017

Tagliarolo, M., and McQuaid, C. D. (2015). Sub-lethal and sub-specific temperature effects are better predictors of mussel distribution than thermal tolerance. Mar. Ecol. Prog. Ser. 535, 145-159. doi: 10.3354/meps11434

Thompson, J. N. (1998). Rapid evolution as an ecological process. Trends Ecol. Evol. 13, 329-332. doi: 10.1016/S0169-5347(98)01378-0

Thompson, R. M., Beardall, J., Beringer, J., Grace, M., and Sardina, P. (2013). Means and extremes: building variability into community-level climate change experiments. Ecol. Lett. 16, 799-806. doi: 10.1111/ele.12095

Torrents, O., Tambutté, E., Caminiti, N., and Garrabou, J. (2008). Upper thermal thresholds of shallow vs. deep populations of the precious Mediterranean red coral Corallium rubrum (L.): Assessing the potential effects of warming in the NW Mediterranean. J. Exp. Mar. Bio. Ecol. 357, 7-19. doi: 10.1016/j.jembe.2007.12.006

Tsounis, G., Rossi, S., Bramanti, L., and Santangelo, G. (2013). Management hurdles for sustainable harvesting of Corallium rubrum. Mar. Policy 39, 361-364. doi: 10.1016/j.marpol.2012.12.010

Tsounis, G., Rossi, S., Gili, J. M., and Arntz, W. (2007). Red Coral Fishery at the Costa Brava (NW Mediterranean): case study of an overharvested precious coral. Ecosystems 10, 975-986. doi: 10.1007/s10021-007-9072-5

Tsounis, G., Rossi, S., Grigg, R., Santangelo, G., Bramanti, L., and Gili, J. (2010). The exploitation and conservation of precious corals. Oceanogr. Mar. 48, 161-212. doi: 10.1201/EBK1439821169-c3

Vezzulli, L., Previati, M., Pruzzo, C., Marchese, A., Bourne, D. G., and Cerrano, C. (2010). Vibrio infections triggering mass mortality events in a warming Mediterranean Sea. Environ. Microbiol. 12, 2007-2019. doi: 10.1111/j.1462-2920.2010.02209.x

Wernberg, T., Bennett, S., Babcock, R. C., De Bettignies, T., Cure, K., Depczynski, M., et al. (2016). Climate-driven regime shift of a temperate marine ecosystem. Science 353, 169-172. doi: 10.1126/science.aad 8745

Conflict of Interest Statement: The authors declare that the research was conducted in the absence of any commercial or financial relationships that could be construed as a potential conflict of interest.

The reviewer GJ and handling Editor declared their shared affiliation, and the handling Editor states that the process nevertheless met the standards of a fair and objective review.

Copyright (c) 2017 Galli, Solidoro and Lovato. This is an open-access article distributed under the terms of the Creative Commons Attribution License (CC BY). The use, distribution or reproduction in other forums is permitted, provided the original author(s) or licensor are credited and that the original publication in this journal is cited, in accordance with accepted academic practice. No use, distribution or reproduction is permitted which does not comply with these terms. 